\title{
Endoscopic Management of Pancreatic Cancer: From Diagnosis to Palliative Therapy
}

\author{
Erika Madrigal and Jennifer Chennat \\ University of Chicago, \\ USA
}

\section{Introduction}

Pancreatic cancer is the fourth leading cause of cancer death in the U.S. According to the Surveillance Epidemiology and End Results (SEER) program, the median age at diagnosis between 2003-2007 was 72 years of age, and the incidence of new cases diagnosed during this period in all races was 13.3 per 100,000 men and 10.5 per 100,000 women. The median age at death for pancreatic cancer during the same period was 73 years of age, and the mortality rate for all races was 12.3 per 100,000 men and 9.4 per 100,000 women. Pancreatic cancer has a $22.5 \%$ 5-year survival rate when localized to the pancreas at diagnosis, and it decreases to $1.9 \%$ when metastasized. The lifetime risk to develop pancreatic cancer is $1.41 \%$, and it is the same for men and women. (National Cancer Institute, 2011) Different types of pancreatic cancers originate from different type of pancreatic cells. About $95 \%$ of pancreatic cancers originate from exocrine cells. Of these, the most common is pancreatic adenocarcinoma (about 95\%). Other less common types of exocrine tumors are: adenosquamous carcinomas, squamous cell carcinomas, giant cell carcinomas, intraductal papillary mucinous neoplasms (IPMN), mucinous cystadenocarcinoma, pancreatoblastoma, cystadenocarcinoma and pseudopapillary tumors. About $5 \%$ of pancreatic cancers originate from endocrine cells, and are known as pancreatic neuroendocrine tumors (NETs). Each of these tumors is named according to the hormone they produce: insulinomas, glucagonomas, gastrinomas, somatostatinomas, VIPomas. (American Cancer Society, 2011) Cystic pancreatic lesions are common and have a wide range of malignant potential. These lesions include, but are not limited to, serous cystadenomas (low potential for malignancy), mucinous cystic neoplasms, and IPMN. Based on the degree of dysplasia, these neoplasms are classified into benign (adenomatous), low-grade malignant (borderline) and malignant (carcinoma in situ and invasive cancer). (Brugge et al, 2004)

Pancreatic cancer must be managed with a multidisciplinary approach. Endoscopy has a primary role in the diagnosis and staging of pancreatic cancer. Endoscopic ultrasound (EUS) is the most frequently used modality for this purpose. Treatment with curative intention involves surgery, with adjuvant therapy (chemotherapy and/ or radiation) in some cases. Most cases are diagnosed when curative resection is not possible. Technologic developments have introduced new endoscopic approaches to the palliation of these advanced cases. 
This chapter will cover the endoscopic technology currently available for diagnosis, staging and palliation of pancreatic cancer. Promising interventional techniques for the diagnosis and palliation of this neoplasia are currently under development and improvement and will also be discussed here.

\section{Diagnosis and staging}

The imaging modalities involved in the diagnosis and staging of pancreatic cancer include Computed Tomography (CT), Magnetic Resonance Imaging (MRI), EUS and Endoscopic Retrograde Cholangiopancreatography (ERCP). Only the endoscopic modalities, EUS and ERCP, will be reviewed here.

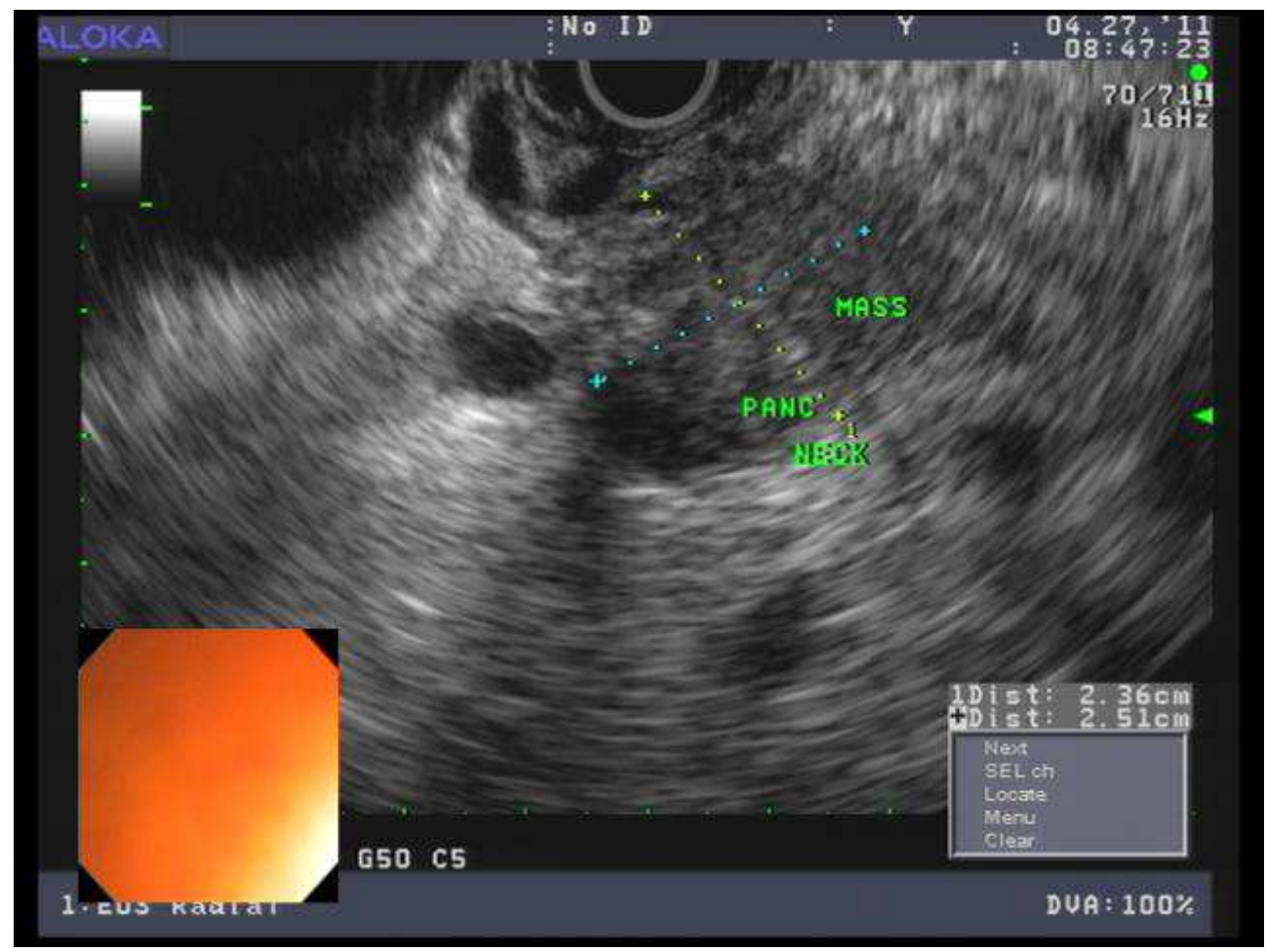

Fig. 1.55 year-old male with a pancreatic mass found in abdominal CT during work up of abdominal pain and weight loss. EUS revealed a $2.5 \mathrm{~cm}$ mass located the neck of the pancreas.

EUS is a combination of endoscopy and intraluminal ultrasound that allows the introduction of high frequency ultrasound waves in the gastrointestinal tract to visualize the wall and adjacent structures. It is considered the procedure of choice for the diagnosis and staging of pancreatic cancer. High resolution endosonographic images can be obtained due to the short distance between the probe and the target lesion. It has become an accepted modality for the diagnosis of pancreato-biliary diseases. (Yamao et al, 2009) EUS has great 
utility in the diagnosis of pancreatic cancer and other gastrointestinal malignancies, as it allows the etiological diagnosis by tissue acquisition by fine needle aspiration (FNA).

EUS is contraindicated in those circumstances where the lesion cannot be clearly visualized, presence of an interposed vessel in the path between the needle and the target lesion, bleeding diathesis and risk of tumor seeding. (Yamao et al, 2009)

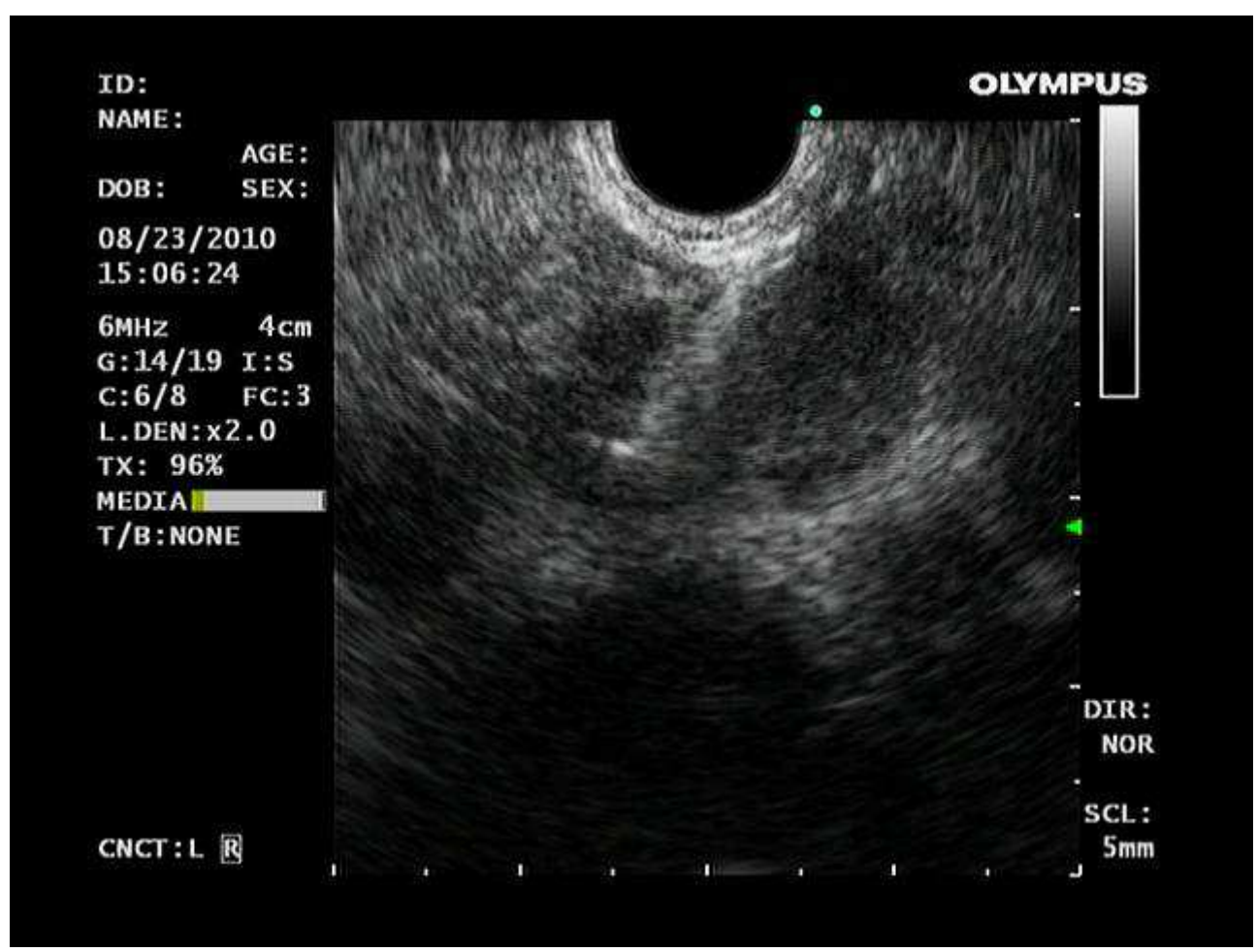

Fig. 2. FNA of a lymph node found during diagnostic EUS in 59 year-old male with metastatic pancreatic adenocarcinoma.

Radial and curve linear array echoendoscopes are available for EUS. Radial echoendoscopes provide a circumferential view at right angle to the shaft of the scope, similar to those provided by CT. The linear array echoendoscope generates longitudinal sector images parallel to the axis of the endoscope giving a $120^{\circ}$ to $180^{\circ}$ scanning view. The linear echoendoscope also has an instrument channel that ranges in size (2.0 to $3.8 \mathrm{~mm})$ and allows not only histological biopsies to be taken by FNA, but also therapeutic interventions that will be discussed later in this chapter. (Yamao et al, 2009; Hawes \& Fockens, 2006) EUS-FNA needles can be locked in a fixed position on the echoendoscope and advanced into the lesion by the endoscopist under ultrasonographic guidance. Needle sizes available are 19, 22 and 25 gauge, and allow for a depth of penetration of up to $10 \mathrm{~cm}$. A 19 gauge trucut needle is also commercially available and allows for the specimens to be processed for immunohistochemical and gene analysis. (Yamao et al, 2009) The 25 gauge needle has the 
advantage of being more flexible and passes through the tissue more easily, however is less echogenic and can be more difficult to visualize during FNA. In the other hand, the stiffness of the 22 gauge needle produces less distortion and probably allows for firmer pressure to be applied. (Hawes, 2010a)

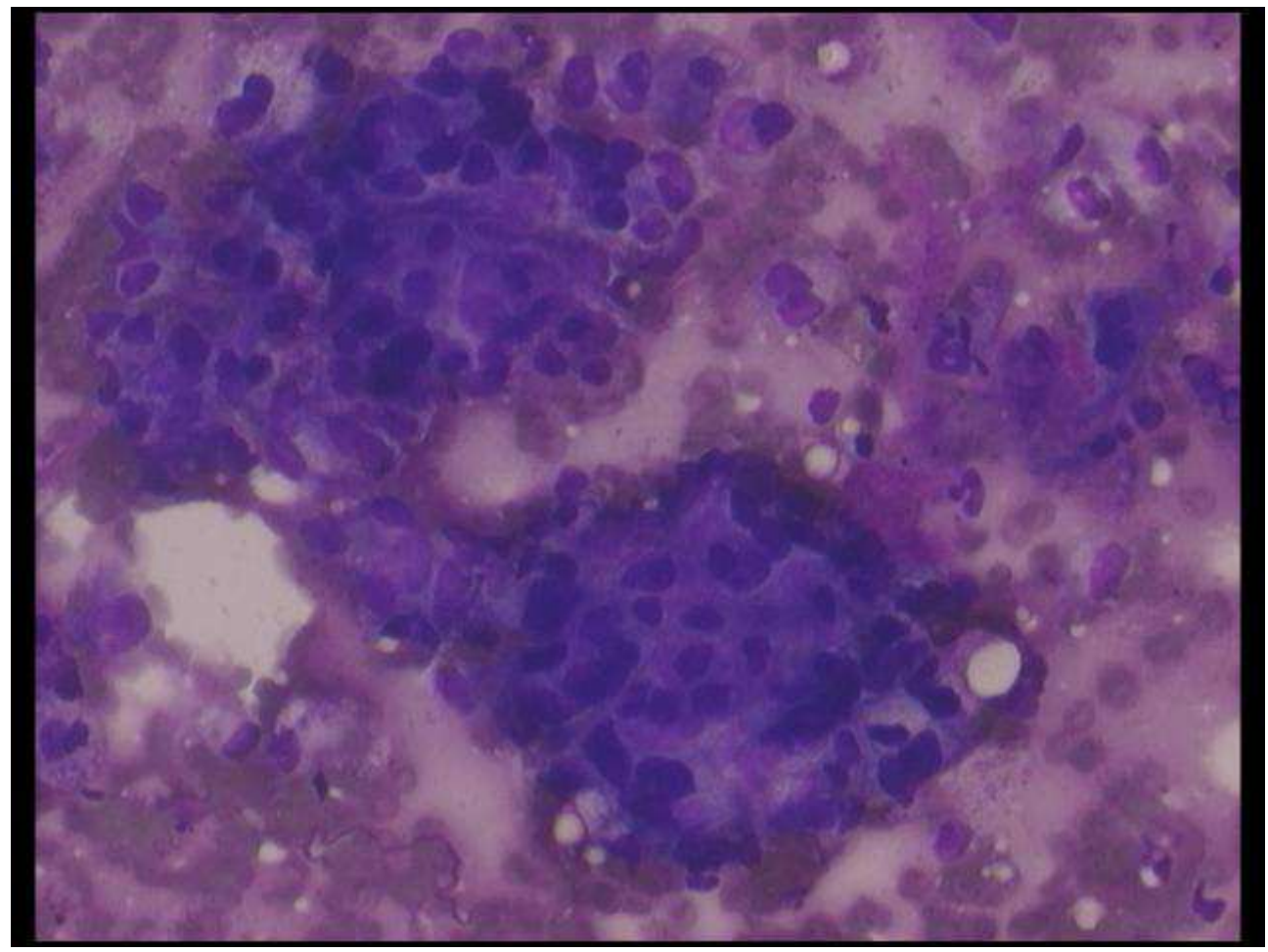

Fig. 3. 55 year-old male with pancreatic neck mass. EUS-FNA was performed and cytology was consistent with adenocarcinoma.

Prior to the development of EUS-FNA, pancreatic FNA or core biopsy were performed either during surgery or percutaneously under US or CT guidance. Intra-operative sampling considerably increases the operating time, and the percutaneous approach has reported sensitivity of about $80 \%$, but at the expense of possible needle-track seeding. (Bret et al, 1986; Ferrucci et al, 1979; Smith et al, 1980; Caturelli et al, 1985) EUS-FNA is associated with high rates of adequate tissue sampling and diagnostic accuracy. A prospective study in 457 patients undergoing EUS-FNA in 554 lesions revealed a sensitivity, specificity, and accuracy of $92 \%, 93 \%$, and $92 \%$ for lymph nodes, $88 \%, 95 \%$, and $90 \%$ for extraluminal masses, and $61 \%, 79 \%$ and $67 \%$ for gastrointestinal wall lesions, respectively. (Wiersema et al, 1997) DeWitt summarized the reports of multiple authors on FNA of pancreatic tumors and reported the accuracy, sensitivity and specificity to be $88 \%, 85 \%$ and $98 \%$, respectively in among nearly 1700 patients (DeWitt, 2006, as cited in Hawes \& Fockens, 2006). Summarizing the results of 23 studies including 1,096 patients over a 21-year period, the sensitivity of EUS for the detection of a pancreatic mass was in the range of $85-100 \%$. (Al-Haddad \& Eloubeidi, 
2010; Yasuda et al, 1988; DeWitt et al, 2004; Chhieng et al, 2002; Eloubeidi \& Tamhane, 2005) The operating characteristics of EUS-FNA of solid pancreatic masses in 547 patients were: sensitivity $95 \%$, specificity $92 \%$, positive predictive value $98 \%$ and negative predictive value $80 \%$, with and overall accuracy of $94.1 \%$. (Eloubeidi et al, 2007) Such accuracy numbers allow for preoperative counseling of patients, minimizing surgeon's operative time in cases of unresectable disease, and avoiding surgical biopsies in those with inoperable disease, also allowing for conservative management of patients with benign pathology results. (Eloubeidi et al, 2007)

To compare the diagnostic yield and complication rates of 22 gauge and 25 gauge needles during EUS-FNA of solid pancreatic masses, a group prospectively randomized 131 patients with suspected pancreatic lesions. (Siddiqui et al, 2009) EUS-FNA with 22 gauge needle was performed in 64 patients and 25 gauge needle was used in 67 patients. Overall, cytology was diagnostic in 120 of 131 patients (91.6\%): 87.5\% with 22 gauge and $95.5 \%$ with 25 gauge. The difference was not statistically different $(p=0.18)$ but there was a trend toward a higher accuracy with the 25 gauge. A similar number of passes was performed in both groups and no complications were reported in either arm.

The 19 gauge Trucut biopsy needle contains an 18mm long specimen tray that acquires larger tissue samples while preserving tissue architecture to allow histologic examination. (Levy, 2007) It was introduced in 2002 and overcomes certain limitations of the FNA needle: certain tumors (stromal tumors, lymphomas and well-differentiated pancreatic tumors) are difficult to diagnose based on cytology alone and the diagnosis accuracy relies on immediate review of the specimen for sampling adequacy by an on-site cytopathologist. When used in conjunction with an echoendoscope, these large caliber needles procure larger specimens for histopathological analysis by means of EUS trucut needle biopsy (EUS-TNB). (Varadarajulu et al 2004) A tissue core sample has several advantages: better distinction between well-differentiated adenocarcinoma and chronic pancreatitis, which accounts for both false-positive and false-negative FNA results; appropriate cellular sub-typing and architectural analysis in the diagnosis of lymphoma, as well as use of special stains, all of which are of limited usefulness with FNA specimens; and elimination of the need for a cytopathologist to assess specimen adequacy, thereby reducing duration and cost of the procedure. (Larghi et al, 2004) A pilot study for the 19 gauge Trucut needle included 18 patients undergoing EUS-FNA and EUS-TNB of different lesions (11 mediastinal masses, 3 pancreatic masses, 3 gastric tumor/ cyst/ lymphoma, and 1 adrenal mass). There was no significant difference in the adequacy of the specimens for evaluation (83\% vs. $100 \%$ adequate specimens in EUS-TNB and EUS-FNA respectively), or in the diagnostic accuracy of EUS-TNB from EUS-FNA (78\% vs. $89 \%$ respectively). Two complications were encountered: one patient required surgery for mediastinitis and another patient was managed conservatively for immediate bleeding. (Varadarajulu et al 2004) A group in London prospectively evaluated the safety and accuracy of EUS-FNA alone vs. combined EUS-FNA and EUS-TNB (EUS-FNA/TNB). (Wittmann et al 2006) A total of 159 patients underwent EUS-FNA alone (lesions $<2 \mathrm{~cm}$ ) or the combination of both modalities (lesions of $2 \mathrm{~cm}$ or more). Adequate samples were obtained in $91 \%, 88 \%$ and $97 \%$ by EUS-FNA, EUSTNB and EUS-FNA/TNB respectively. From the pancreas $(n=83)$, adequate samples were obtained by FNA in $94 \%$ and by TNB in $81 \%$, compared with $87 \%$ and $92 \%$ from nonpancreatic sites $(n=76)$ respectively. Overall accuracy for EUS-FNA alone was $77 \%$, for 
EUS-TNB alone $73 \%$ and for EUS-FNA/TNB 91\% $(p=0.008)$. For pancreatic sampling, the accuracy of FNA alone was $77 \%$, for TNB alone was $56 \%$ and for FNA/TNB $83 \%$. For nonpancreatic sampling, the accuracy for EUS-FNA alone was 78\%, for EUS-TNB alone $83 \%$ and for EUS-FNA/TNB 95\% ( $\mathrm{p}=0.006$ ). The complication rate was $0.6 \%$ (one patient with moderate self-limited abdominal pain and another patient with bile leak requiring endoscopic stent replacement). Another group prospectively enrolled 247 patients to determine factors predicting a positive diagnostic yield and the safety of EUS-TBN. (Thomas et al, 2009) The lesions sampled were in the pancreas (113), esophagogastric wall (34), and extrapancreatic areas (100; 52 of those were lymph nodes). The overall accuracy was 75\%. The overall complication rate was $2 \%$ (bronchopneumonia, minor hemoptysis, minor hematemesis, mucosal tear, retropharyngeal abscess) with no procedure-related deaths. A higher diagnostic yield was found when the lesion was approached through the stomach and when more than two passes were made. With the aim of comparing EUS-FNA using 25 gauge and 22 gauge needles with the EUS guided 19 gauge Trucut needle in solid pancreatic mass, a group in Japan prospectively enrolled 24 patients. (Sakamoto et al, 2009) The 25 gauge EUS-FNA was technically easier and obtained superior overall diagnostic accuracy, especially in lesions of the pancreas head and uncinate process. Overall accuracy for the 25 gauge, 22 gauge and Trucut needle was $91.7 \%, 79.7 \%$ and $54.1 \%$, respectively. Accuracy for cytological diagnosis irrespective the site of lesions with 25 gauge, 22 gauge and Trucut needles was $91.7 \%, 75 \%$ and $45.8 \%$, respectively. For uncinate masses, it was $100 \%, 33.3 \%$, and $0 \%$ respectively.

Most endosonographers consider EUS-FNA the procedure of choice for sampling of pancreatic masses, however, EUS-TNB has a role in selected settings. The most clear advantage of EUS-TNB over EUS-FNA is in the diagnosis of disorders for which histology is necessary and cytology is inadequate, such as autoimmune pancreatitis and chronic 'nonspecific' pancreatitis. For other pancreatic disorders including cystic pancreatic tumors, islet cell tumors, secondary metastatic solid pancreatic tumor, and primary solid pancreatic tumors, EUS-TNB and EUS-FNA have often complementary roles. (Levy, 2007)

Pancreatic masses found in the background of chronic pancreatitis present a particular challenge to endoscopists. Better methods to detect pancreatic tumors in this setting and to better target the fine needle aspiration within a pancreatic mass to optimize sampling are needed. The development of image enhancing techniques and/or the use of contrast agents may fulfill these needs. Elastography is a method for real-time evaluation of tissue stiffness. Elastography uses a hue color map (red-green-blue) to display tissue stiffness: hard or stiff tissue is shown in dark blue, medium hard tissue areas in cyan, intermediate hardness tissue areas in green, medium soft tissue areas in yellow and soft tissue in red. (Hawes, 2010) A group from Spain reported the use of EUS elastography for the characterization of solid pancreatic masses in 130 patients and compared them with 20 normal controls. Four elastographic patterns were described, with high concordance among the 2 blinded investigators. A green-predominant pattern (homogeneous or not) excluded malignancy with high accuracy whereas a blue-predominant pattern (homogeneous or heterogeneous) supported a malignancy diagnosis. Sensitivity, specificity and overall accuracy for the diagnosis of malignancy were 100\%, 85.5\% and 94\% respectively. (Iglesias-Garcia et al, 2009) A Japanese group investigated the usefulness of EUS combined with contrast enhancement in the preoperative localization of pancreatic endocrine tumors (PET) and the differentiation 
between malignant and benign PETs. (Ishikawa et al, 2010) This group retrospectively studied 62 pathologically confirmed PETs found in 41 patients who had undergone EUS, multiphasic multidetector computed tomography (MDCT) and transabdominal ultrasound (US). Contrast-enhanced EUS had 95\% sensitivity in identifying PETs compared with $80 \%$ with MDCT and 45\% with US. Heterogeneous ultrasonographic texture was the most significant factor for malignancy. It was also noted that when contrast was used with EUS, PETs showed contrast enhancement except in areas of hemorrhage or necrosis. The optimal use of elastography and contrast enhanced EUS would be to define an optimal target area within a pancreatic mass to maximize the cytologic yield. (Hawes, 2010)

Cystic pancreatic lesions are commonly found nowadays given the development and availability of different imaging tests that are often performed for unrelated reasons. Cystic lesions are sometimes difficult to diagnose. Cross-sectional imaging is often non-diagnostic due to the small size of the cystic lesions. EUS has become useful for the diagnosis of these lesions as it provides high resolution images and allows the performance of FNA of the cystic fluid for cytology and tumor marker determinations. A large, prospective multicenter study looking at the imaging, cyst fluid cytology and cyst fluid tumor markers found that

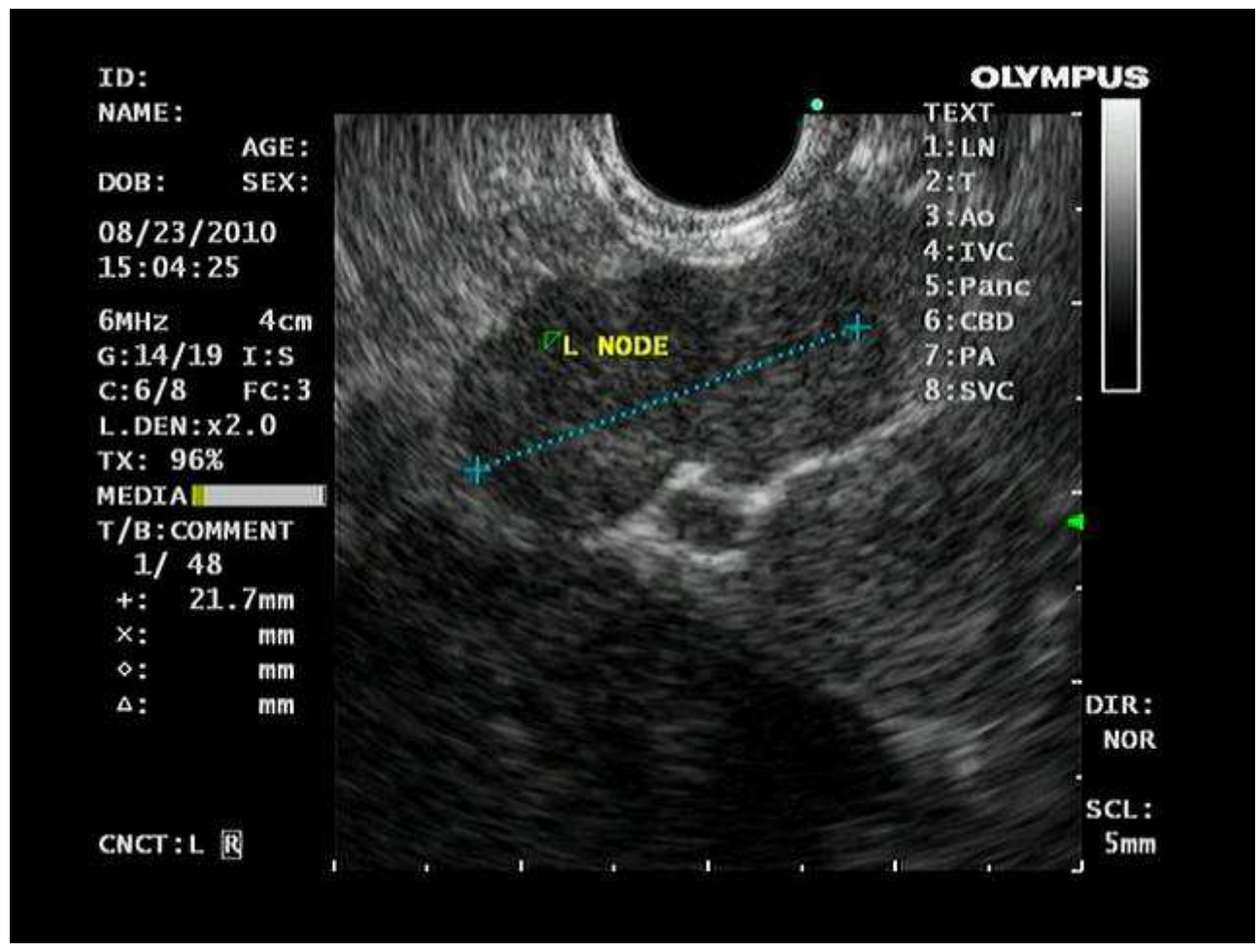

Fig. 4. The picture demonstrates one of the multiple peri-pancreatic lymph nodes found in a patient with metastatic pancreatic adenocarcinoma. The largest measured $25 \mathrm{~mm}$. FNA of the lymph node was performed and cytology was consistent with poorly differentiated adenocarcinoma. 
the cystic fluid CEA (using a cutoff value of $192 \mathrm{ng} / \mathrm{mL}$ ) was able to differentiate mucinous vs. nonmucinous cystic lesions with an accuracy of $79 \%$, which was significantly higher than the accuracy of EUS morphology $(51 \%)$ or fluid cytology $(59 \%)(p<0.05)$. (Brugge et al, 2004b)

Staging of pancreatic malignancy is done according to the American Joint Committee for Cancer (AJCC) Staging TNM classification. This describes the tumor extension (T), lymph node $(\mathrm{N})$ and distant metastases $(\mathrm{M})$ of tumors, respectively. Accuracy of the $\mathrm{T}$ staging by EUS ranges from $63 \%$ to $94 \%$ and nodal $(\mathrm{N})$ staging ranges from $41 \%$ to $86 \%$, (DeWitt et al, 2004; Palazzo et al, 1993; Gress et al, 1999; Rivadeneira et al, 2003) which is superior to CT and trans abdominal ultrasound. (Palazzo et al, 1993; Gress et al, 1999; Rivadeneira et al, 2003; Agarwal et al, 2004) Comparative studies between EUS and cross-sectional imaging have generally shown that EUS is superior for local tumor staging ( $\mathrm{T}$ and $\mathrm{N}$ ) in esophageal, pancreatic and rectal cancer, but CT is still necessary for full assessment of metastatic disease. (Hawes, 2010) EUS, however, can be of value when evaluating for metastases. Part of the liver can be visualized by EUS and suspected metastatic lesions can be sampled. Celiac lymph nodes can also be biopsied if appearing suspicious and ascites can be aspirated and sent for cytology to assess for peritoneal metastases. (Al-Haddad \& Eloubeidi, 2010)

EUS is associated with a low rate of complications. A study in 322 patients and 345 lesions revealed an overall complication risk of $1.6 \%$. This study involved pancreatic EUS-FNA in 248 cases (134 solid lesions and 114 cystic lesions) and complications were observed in 4 (1.2\%) patients with pancreatic cystic lesions (acute pancreatitis in 3, and aspiration pneumonia in 1). No complications resulted from FNA of solid pancreatic lesions. (O'Toole et al, 2001) Despite the low complication risk, life threatening complications have been sporadically reported: fulminant cholangitis after FNA of a liver metastasis and uncontrolled bleeding from a pseudoaneurysm after pancreatic FNA, (Erickson, 2004) massive bleeding from a gastric GIST (Inoue et al, 2006) and acute portal vein thrombosis after FNA of pancreatic cancer. (Matsumoto et al, 2003) A prospective cohort study in 355 patients evaluated the frequency of major complications following EUS-FNA of solid pancreatic masses and found major complications in $2.54 \%$ with acute pancreatitis developing in 3 patients $(0.85 \%)$. (Eloubeidi et al, 2006)

ERCP played a major role in the diagnosis of pancreatic disease since its development in the late 1960s. However, the introduction and advances of imaging studies, especially MRCP, have shifted the ERCP applications toward therapeutic interventions. ERCP is seldom performed for diagnostic purposes, but it provides detailed opacification of the main and branch ducts (pancreatogram). The morphologic changes in the ductal system usually correlate with histologic changes. This is limited in the case of cysts that do not communicate with the pancreatic duct. ERCP also allows collection of pure pancreatic juice for cytology and gene analysis, brush cytology, biopsy of the pancreatic duct, and introduction of baby scopes or ultrasonic probes into the pancreatic duct for pancreatoscopy and intraductal ultrasound (IDUS), respectively. (Fujita et al, 2004)

Pancreatography can suggest the diagnosis of pancreatic cancer. A Japanese study comparing the pancreatographic findings of autoimmune pancreatitis and cancer revealed that an obstructed main pancreatic duct and an upstream duct dilation to a diameter greater than $4 \mathrm{~mm}$ were significantly more common in cancer cases; meanwhile, autoimmune pancreatitis had a higher prevalence of narrowing of the main pancreatic duct for more than 
$3 \mathrm{~cm}$ of its length and a higher prevalence for the presence of side branches in the narrowed portions if the main pancreatic duct. (Nishino et al, 2010) The pancreatographic features suggestive of pancreatic cystic neoplasms include displacement of the pancreatic duct, pancreatic duct strictures, and the degree of pancreatic ductal obstruction. In the case of IPMN, the main pancreatic duct may be dilated diffusely or in a segment fashion depending on the volume of mucus produced, the presence of ductal obstruction and the presence and distribution of intraductal tumors. Enlargement of the main pancreatic duct is a frequent pancreatographic abnormality in IPMN, present in about $77 \%$ of patients; side branch ectasia or cystic dilation occurs in about $51 \%$ of the cases. (Telford \& Carr-Locke, 2002)

Pancreatic juice and mucus can be aspirated directly from the pancreatic duct during ERCP, either by catheter or pancreatoscopy. Stimulation of pancreatic exocrine secretion by administration of secretin may improve the diagnostic yield. The samples are sent for cytology, as well as analysis of mucin, tumor marker levels, and amplification of molecular abnormalities. (Telford \& Carr-Locke, 2002) Examination of the pancreatic juice collected during cannulation yielded positive results in $52.3 \%$ of pancreatic cancer patients. Higher positive rates were obtained when washing with saline $(63.2 \%)$ and aspirating after secretin stimulation $(51.3 \%)$, as well as in cases of pancreatic head cancer $(70.6 \%)$. (Kameya et al, 1981) For IPMN, the specificity of the cytology of the pancreatic juice is $100 \%$, and the sensitivity is $62.2 \%$ when collected by pancreatoscopy and $38.2 \%$ when collected by catheter. (Chen 2007; Yamaguchi et al, 2005)

Brush cytology of pancreatic duct strictures or elevated intraductal lesions during ERCP has a sensitivity and specificity to detect malignancy of $48-76 \%$ and $100 \%$, respectively, and accuracy of 70-76.4\%. (Telford \& Carr-Locke, 2002; Chen 2007; Ferrari et al, 1994; Vandervoort et al, 1999; Uchida et al, 2007) Accuracy may be influenced by location of sampling within the pancreas, technical errors and interpretation of the sample. (Chen 2007) Strictures located at the head and body of the pancreas usually yield high rates of positive cytology. The diagnostic yield is overall enhanced by concomitant brushing of pancreatic and bile duct strictures. (McGuire et al, 1996) A retrospective study evaluating the diagnostic yield of combining EUS-FNA with brushing cytology during the work up of pancreatic cancer revealed that the combined use of these two modalities provides a better diagnostic yield in pancreatic adenocarcinoma than either one alone. The sensitivity, specificity and accuracy were $69.2,93.8$, and $77.3 \%$ for EUS-FNA alone, 50.8, 100, and 67\% for brushing cytology alone, and 84.6, 100, and 89.7\% for combination of EUS-FNA with brushing cytology. (Jing et al, 2009) A recent study to determine whether KRAS (protooncogene) mutations could be identified in pancreatobiliary stricture brushings and to compare the performance characteristics of KRAS mutation analysis to cytology and fluorescence in situ hybridization (FISH) for detection of carcinoma revealed that combined KRAS mutation and FISH analysis appear to increase the cancer detection rate in patients with pancreatobiliary strictures. The KRAS mutation and polysomic FISH (positive) results were identified in $69 \%$ and $63 \%$ pancreatic adenocarcinoma specimens, respectively, with a combined sensitivity of $86 \%$. (Kipp et al, 2010) In the case of cysts, a new through the needle cytological brush system (Echo-Brush) seeks to solve the poor cellularity typically obtained by EUS-FNA. This system consists in the introduction of the brush through a 19 gauge EUS needle after aspiration of the cyst fluid. The brush is used to scrub the cystic wall and is processed as standard brushing. Studies have had conflicting results. A group from Spain found that the brush was superior to the aspirated fluid for detecting diagnostic cells but 
didn't reach statistical significance ( $73 \%$ vs. $36 \%$, p=0.08). In terms of mucinous cells, the yield of the cytobrush was significantly higher ( $50 \%$ vs. $18 \%$, p=0.016). (Sendino et al, 2010) A group from the United Kingdom evaluating the management of cystic pancreatic lesions reported a similar cellularity yield between the FNA group and the brushing group $(61.9 \%$ and $55.0 \%$, respectively). Greater proportion of patients with malignant cystic lesions diagnosed by EUS sampling were in the brushing group, but this did not reach significance ( $50 \%$ in the brushing group vs. $20 \%$ in the FNA group, $\mathrm{p}=0.524$ ). (Thomas et al, 2010)

Random transpapillary biopsies of the pancreatic duct can be obtained in the presence of a stricture or an elevated lesion. The specificity for the detection of malignancy approaches $100 \%$, but the sensitivity is variable, ranging from $57 \%$ to $100 \%$. The accuracy of these biopsies increases when performed during pancreatoscopy. (Telford \& Carr-Locke, 2002; Chen, 2007)

Pancreatoscopy is the endoscopy of the pancreatic duct, and it is performed using a motherbaby scope system: a thin endoscope (baby scope) is introduced into the pancreatic duct through the working channel of the duodenoscope (mother scope). This technique has some limitations for small size pancreatic ducts: the wider the scope diameter, the better the quality of images; the tip-bending system, useful for observing the tortuous pancreatic ductal lumen, increases the size of the scope; the use of irrigation and suction system is needed to achieve a good endoscopic view, but also increases the size of the scope. Given these size limitations, the investigation of IPMN is the best indication for the use of pancreatoscopy. (Fujita et al, 2004) The insertion of the pancreatoscope is facilitated by the frequently enlarged papillary orifice present in IPMN. Pancreatoscopy in this condition allows for endoscopic diagnosis in 67\% to 83\%, (Nguyen et al, 2009) differentiation of a filling defect seen in pancreatography as mucus, tumor or stone, identification of malignant features, endoscopic biopsy, and determination of disease extent. Clusters of papillary projections in IPMN rising $<3 \mathrm{~mm}$ above the ductal surface can represent hyperplasia or adenoma with different degrees of dysplasia. In the other hand, adenocarcinoma is typically polypoid and protrudes $>3 \mathrm{~mm}$ into the ductal lumen. Diffuse hyperemia or distinct vessels may also be observed and are also considered high-risk features. (Telford \& Carr-Locke, 2002) The cancer detection rate by pancreatoscopy-guided sampling has a sensitivity of $62.5 \%$, specificity $100 \%$, positive predictive value $100 \%$, and negative predictive value $70.7 \%$. (Iqbal \& Stevens, 2009) Despite the usefulness of this diagnostic tool, pancreatoscopy requires expensive, very fragile equipment and two experience endoscopists to operate it. Hence, it is not performed often. (Telford \& Carr-Locke, 2002)

IDUS uses a thin caliber (approximately $2 \mathrm{~mm}$ in diameter) ultrasound probe with highfrequency ultrasound (12-30 MHz). For pancreatic IDUS, the ultrasonic probe is advanced into the pancreatic duct over a guidewire during an ERCP. However, in some situations it is not possible for even a thin caliber prove to pass a stenotic site caused by a mass in the pancreatic duct. (Fujita et al, 2004) A study comparing the detection rates of different imaging technologies in patients with mucin-producing tumors revealed a detection rate of $21 \%$ for CT, $29 \%$ for ultrasound, $83 \%$ for pancreatoscopy, $86 \%$ with EUS, and $100 \%$ for IDUS. (Chen, 2007) IDUS is useful in assessing the indications for surgery by revealing mural nodules in mucinproducing tumors, evaluating the feasibility of partial resection of the tumor, locating multiple lesions in pancreatic islet-cell cancer, and differentiating benign from malignant cases of localized stenosis of the main pancreatic duct. (Furukawa et al, 1997) 
Cancer detection rate can be improved by techniques that allow better visualization, such as narrow-band imaging (NBI) or by developing techniques that image the lesion at microscopic level, such as confocal laser microscopy. NBI during pancreatoscopy has been shown to provide better visualization of vascular pattern and tumor vessels than conventional white light. (Iqbal \& Stevens, 2009) Some authors have reported the ability of NBI to identify both the surface structure and mucosal vessels as good as, or even better than, conventional white light, regardless of benign or malignant etiology. (Itoi et al, 2009)

The use of a confocal microscope enables subsurface in vivo histological assessment during ongoing endoscopy. This technology also requires the application of a flourophore for mucosal fluorescence imaging. Endomicroscopic images can be acquired after intravenous application of fluorescein, which also makes the blood vessels clearly visible. The use of this technology in the investigation of biliary pathologies has escalated since the introduction of a flexible probe-based confocal laser endomicroscopy (pCLE) system. Certain hallmarks and patterns have been identified to differentiate benign from malignant epithelium. (Meining, 2009) The experience in pancreatic pathologies is more limited and developing. A group was able to use pCLE to detect and further differentiate pancreatic strictures such as IPMN. (Meining et al, 2009) The use of this technology may be helpful to clarify location and types of IPMN for a targeted surgical resection. Confocal endomicroscopy is being developed further and a new miniprobe small enough to be introduced through a 22 gauge puncture needle was developed. Feasibility studies to evaluate the ability of this needle-based confocal laser endomicroscopy (nCLE) for in vivo histology of various organs, including pancreas, have been carried in animal models with good results. (Becker et al, 2010; Mennone \& Nathanson, 2011) A multicenter trial assessing the use of nCLE in humans is currently being carried.

\section{Therapeutic Interventions}

Endoscopy has no role in the treatment of pancreatic cancer, as the only definite treatment is surgical resection when the disease is diagnosed in early stages. For advanced cases, palliation is indicated and endoscopy plays an important role. The procedures currently performed for palliation of pancreatic cancer involve stent placement for the drainage of biliary or pancreatic duct obstruction by ERCP or under EUS guidance, celiac plexus neurolysis (CPN), injection of anti-tumor agents, and implantation of fiducial markers to guide radiation therapy. Other experimental procedures are being developed to evaluate the role of EUS in the application of radiofrequency ablation (RFA) and photodynamic therapy (PDT).

ERCP for drainage of biliary obstruction is the most commonly performed endoscopic procedure for palliation of pancreatic cancer. Endoscopic treatment of these malignant biliary obstructions is often successful in alleviating symptoms such as jaundice and pruritus, reducing the incidence of cholangitis, and increasing biliary drainage so that hepatically metabolized chemotherapeutic agents can be offered. (Rogart, 2010) The first biliary stents available were made of polyethylene (plastic), and had the drawback of occlusion with sludge in about $30 \%$ of cases, resulting in recurrence of symptoms and development of cholangitis. Self-expanding metal stents (SEMS) had previously been used for vascular and urethral indications, and were later developed for biliary applications. Initial non-comparative studies reported an occlusion rate of SEMS of 10-18\%. In 1992, the 

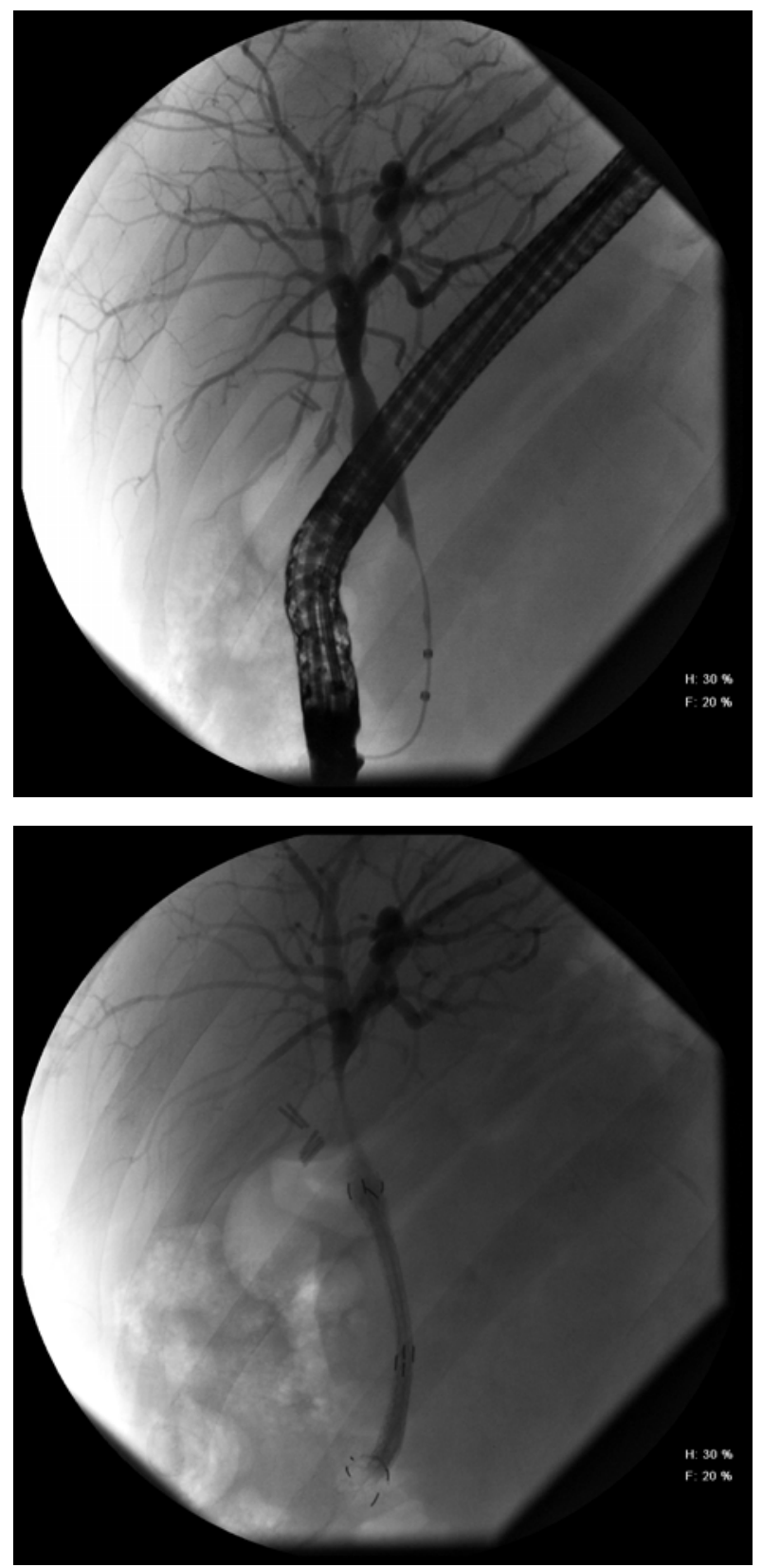

Fig. 5. 59 year-old male with biliary obstruction secondary to pancreatic head mass (adenocarcinoma). An ERCP was performed and a distal common bile duct stricture can be appreciated in the left image. The patient had metastatic disease, and a SEMS was placed for palliation of jaundice and pruritus. 
first prospective randomized clinical trial reporting the patency and cost-effectiveness of SEMS vs. plastic stents was published: the median patency of the stent was significantly prolonged in patients with metal stent compared with those with a polyethylene stent (273 days vs. 126 days, $p=0.006$ ), and the incremental cost-effectiveness analysis showed that initial placement of a SEMS results in a $28 \%$ decrease of endoscopic procedures. (Davids et al, 1992) Since the introduction of biliary SEMS, several groups have concluded that their placement represent a cost-saving strategy, as plastic stents are associated with higher risk of recurrent biliary obstruction, which translates into additional procedures, hospitalizations, etc. (Arguedas et al, 2002; Kaassis et al, 2003; Moss et al, 2006) There was initial concern on the possibility of interfering with subsequent pancreaticoduodenectomy after biliary metal stent placement in patients with uncertain surgical status or with resectable masses, but this has not been well substantiated. There are actually some reports on the cost-benefit that these stents offer to these patients, as well as the longer patency rate, need for fewer procedures and fewer episodes of cholangitis. (Rogart, 2010; Wasan et al, 2005; Chen et al, 2005; Boulay et al, 2010) In addition, insertion of SEMS is advised as the treatment of biliary SEMS occlusion, as it provides longer patency and survival, decreases the number of subsequent procedures by $50 \%$ (compared to plastic stents) and is costeffective. (Rogart et al, 2008)

However, technical failure during ERCP is encountered in up to $10 \%$ of cases due to various factors including duodenal obstruction, anatomical variations, periampullary diverticulum and tightness of the stricture. In these cases, percutaneous transhepatic biliary drainage (PTBD) and surgical drainage are options available. The technical success rate for PTBD placement is $90 \%$ if the intrahepatic system is dilated and $70 \%$ in a non-dilated system. The morbidity is $7 \%$ and the mortality is $5 \%$, and it is contraindicated in the presence of ascites and coagulopathy. Surgical drainage, although a possibility, is associated with high morbidity and mortality rates (66\% and $32 \%$, respectively), as the patients in need for this procedure are usually very deconditioned. Hence, the drainage of the biliary system using a transgastric or transduodenal approach under EUS guidance has been introduced with a reported technical success rate of $92 \%$. Once the common bile duct (CBD) is localized from the duodenal bulb or the intrahepatic system is visualized from the stomach, the biliary system is accessed under EUS guidance and a stent is deployed under fluoroscopic guidance to form a choledochoduodenostomy or a hepaticogastrostomy, respectively. The reported technical success rate for hepaticogastrostomy is $90-100 \%$ and the clinical success rate is $75-100 \%$. The complication rate associated with EUS-guided biliary drainage is $19 \%$, with $8 \%$ being due to focal biliary peritonitis. Other complications include bleeding, pneumoperitoneum, infection caused by stent occlusion/migration, and death. (Ramesh \& Varadarajulu, 2008; Irisawa et al 2009) Plastic stents are the most commonly used during this approach; however, transduodenal and transgastric placement of self-expandable metal stents (SEMS) for palliation of malignant biliary obstruction has been reported and some authors report antegrade placement achieving transpapillary or, in case of post-surgical anatomy, transanastomotic placement. (Siddiqui et al, 2011; Nguyen et al, 2010; Artifon et al, 2010)

EUS-guided pancreatic duct drainage can also be accomplished. There are two techniques: 1) transmural drainage of the main pancreatic duct; and 2) rendezvous approaches for ERCP assistance of transpapillary drainage. (Irisawa et al, 2009) The main indication for the pancreatic duct drainage is to alleviate pain caused by pancreatic ductal obstruction 
associated with chronic pancreatitis and other inflammatory processes. For this reason, this will not be discussed further in this chapter.
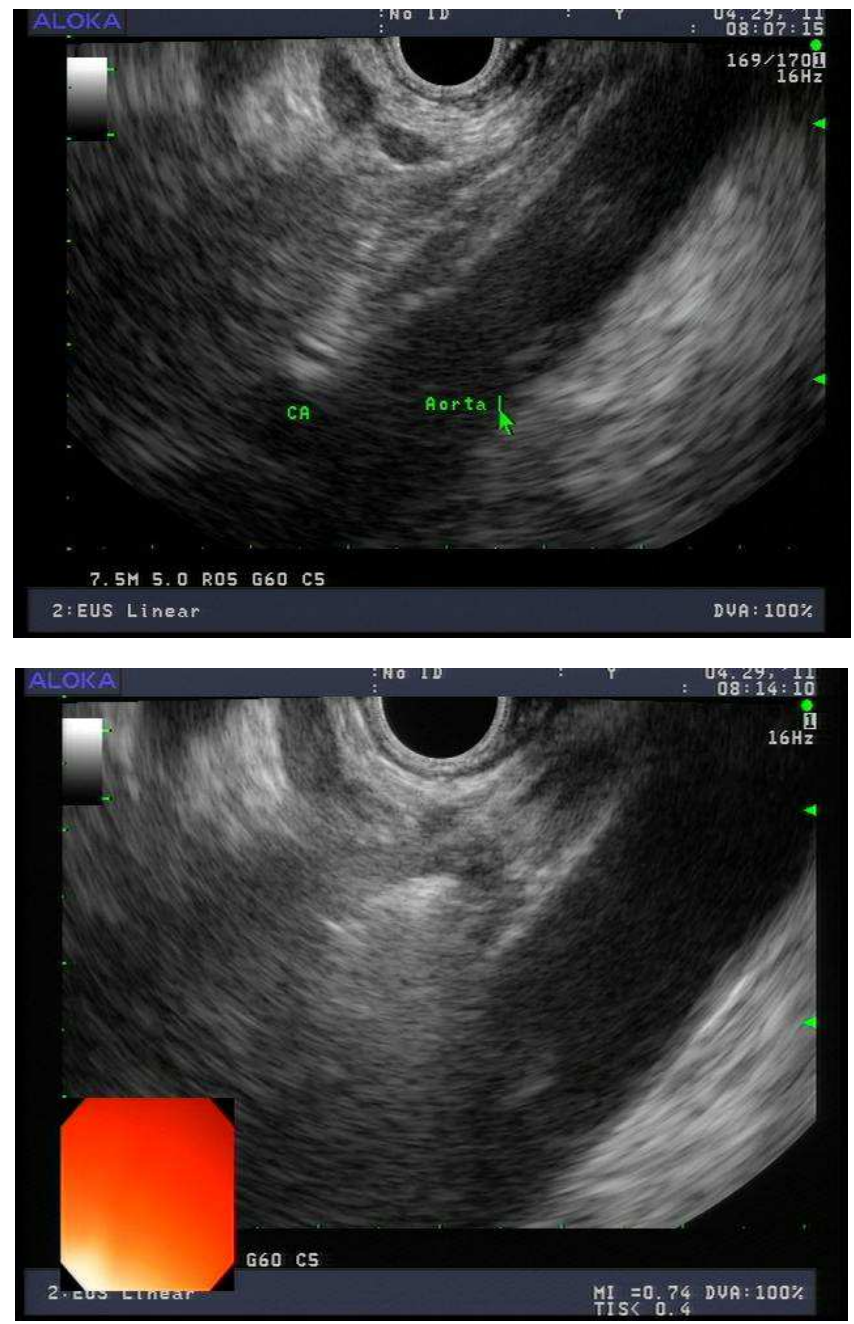

Fig. 6. 40 year-old female with locally advanced pancreatic cancer and severe abdominal pain with poor response to narcotics. Patient had EUS guided CPN. Celiac axis is localized under EUS (left image) and absolute alcohol was then injected to both sides of the celiac axis (seen as a white cloud surrounding the aorta in the right image).

Pain is reported in the majority of patients with advanced pancreatic cancer (90\%), and effective pain control can be achieved in $70-90 \%$ of these patients with CPN. (Ramesh \& Varadarajulu, 2008; Puli et al, 2009; Kaufman et al, 2010) This procedure entails the injection of absolute alcohol under EUS guidance to destroy the sympathetic plexus near the celiac axis. A similar technique involving the injection of triamcinolone is performed in patients 
with chronic pancreatitis for pain control. (Ramesh \& Varadarajulu, 2008) Significant reduction of pain scores 12 weeks after CPN was observed in 30 patients with advanced intra-abdominal malignancy, while $91 \%$ of these patients required same or less pain medication and $88 \%$ of patients had persistent improvement in their pain score. (Wiersema et al, 1996) Similarly, in another study of 58 patients with unresectable pancreatic cancer, EUS-guided CPN lowered pain scores in $78 \%$ at 2 weeks and a sustained response was noted until 24 weeks. (Naresh et al, 2001) The most commonly reported complications after CPN are orthostatic hypotension in 10-15\% and transient diarrhea in 9\%. (Gunaratnam et al, 2001) Recently, a retrospective analysis to determine predictors of response to CPN in a cohort of 64 patients with pancreatic cancer revealed that visualization o the celiac ganglia was the best predictor of response: patients with visible ganglia were $>15$ times more likely to respond ( $\mathrm{p}<0.001)$. (Ascunce et al, 2011)

Percutaneous ethanol injection is an effective treatment for cystic and solid lesions in the liver. Successful ethanol ablation of cysts in the thyroid, parathyroid, kidneys, and spleen have been reported with minimal side effects. EUS offers minimally invasive access to perform ablation of pancreatic lesions. This EUS-guided ablative therapy may have important clinical applications in the treatment of solid (adenocarcinomas, neuroendocrine tumors) and cystic pancreatic lesions (mucinous cystic neoplasm, IPMN), especially in nonoperative candidates. A pilot study in porcine models showed that ethanol injection into normal porcine pancreas results in focal inflammation, necrosis and fibrosis at the injection site. (Aslanian et al, 2005) Another pilot study reported the safety and feasibility in humans, after 25 patients underwent ethanol lavage of different cystic pancreatic lesions (mucinous cystic neoplasms, IPMNs, serous cystadenomas, and pseudocysts) with no side effects or complications reported in short and long-term follow up. (Gan et al, 2005) The approach to this technique involves aspirating the cyst content with a 22 gauge needle until collapse is achieved. Ethanol is then injected into the cyst, and the cyst is lavaged for 3 to $5 \mathrm{~min}$. The cystic lesion is finally drained of fluid at the conclusion of the lavage. (Trevino \& Varadarajulu, 2011) Studies in animals have revealed that EUS-guided injection of ethanol into the pig pancreas results in a localized concentration-depended tissue necrosis without complications, with a visible necrotic area of $20.8 \mathrm{~mm}(+/-4.3 \mathrm{~mm})$ after injection of $40 \%$ to $100 \%$ ethanol. (Matthes et al, 2007) A small study demonstrated no cyst recurrence by CT after a median follow up of 26 months (including suspected mucinous cysts). However, longer follow up is still needed before considered these patients cured. (DeWitt et al, 2010) The main potential problem of EUS-guided ethanol ablation is the risk of acute pancreatitis due to diffusion of alcohol outside the lesion into the main pancreatic duct and/or the pancreatic parenchyma. (Giovannini, 2007)

EUS-guided fine needle injection (FNI) has been proposed as a new technique for delivery of anti-tumor agents for patients with locally advanced malignancy. Few small size studies (8-37 patients) have been published, reporting the safety and feasibility of direct injection of different agents, such as allogenic mixed lymphocyte culture or cytoimplant (cytokine production within a tumor may lead to regression by host immune mechanisms, and cytoimplants produce such a cytokine response), ONYX-015 (adenovirus that selectively replicates and kills malignant cells) and TNFerade [replication-deficient adenovector containing the human tumor necrosis factor (TNF)- $\alpha$ gene, regulated by radiation-inducible promoter Egr-1]. The commonly reported side effects are low grade fever without 
leukocytosis, nausea, abdominal pain and elevated liver enzymes and bilirrubin. No pancreatitis has been reported, but few cases of sepsis and two cases of duodenal perforation occurred prior to the institution of prophylactic antibiotic and due to the rigid endoscope tip during transduodenal approach, respectively. These studies revealed partial response or at least tumor stabilization. Perhaps combination of systemic chemotherapy and/or radiation with EUS-FNI would improve outcomes. This field will continue to expand with the refinement of echoendoscopes, delivery systems and novel local antitumor agents. (Trevino and Varadarajulu, 2010; Klapman \& Chang, 2005; Verna \& Dhar, 2008; Chang, 2006)

Implantation of fiducial markers to facilitate stereotactic radiotherapy and radioactive seeds for brachytherapy can be performed under EUS guidance. Fiducials can be placed into tumors to enable higher doses of targeted radiotherapy while sparing adjacent healthy tissue with low risk of complications. This technique has a reported technical success rate of $84-94 \%$, and its direct impact on patient management is promising but still under clinical investigation. A total of 3-6 gold fiducials are placed within the tumor in different planes under EUS guidance. Immediate complications are uncommon and involve needle malfunction and minor bleeds with no significant drop in hemoglobin. Although fiducials can spontaneously migrate from the initial injection site, the reported rate of migration is low $(7 \%)$, and no migration-related complications have been documented. (Ramesh \& Varadarajulu, 2008; Park et al, 2010; Sanders et al, 2010) The EUS-guided placement of fiducials has traditionally involved the use of 19 gauge needles. However, a recently published case series reported the feasibility of using a 22 gauge needle, which may permit greater access when compared to a 19 gauge needle technique. (Ammar et al, 2010) Brachytherapy is a useful method for local control of malignant tumors, including pancreas. After the placement of the radioactive seeds, the tissue is exposed to steady radiation, leading to localized ablation and avoiding the radiation of normal tissues surrounding the malignant lesion. EUS-guided brachytherapy has been performed to place radioactive iodine seeds into the locally advanced pancreatic tumor mass, with significant improvement in pain scores and also improvement in performance status scores. When assessing the tumor response, an $80 \%$ rate of positive response (decrease in tumor size) or stable disease has been reported. Hematologic toxicity is usually mild, but includes neutropenia, thrombocytopenia, and anemia. Other reported complications reported less frequently are pancreatitis and pseudocyst formation. (Sun et al, 2006) Small size studies have demonstrated the technical feasibility of EUS-guided implantation of radioactive seeds in pancreatic tumors, and the technique appears to be well tolerated. (Ramesh \& Varadarajulu, 2008; Sun et al, 2006) However, larger studies evaluating this technique and its role in a multimodality approach in combination with chemotherapy and/ or external beam radiation are needed.

Radiofrequency ablation (RFA) is a well-established procedure that provides palliation for various malignant diseases. RFA causes a relatively predictable zone of coagulation necrosis by intense tissue heating. Accurate and precise targeting of the tumor is important to maximize the yield and minimize the morbidity. (Klapman \& Chang, 2005) This technique is emerging as one of the safest and most predictable for thermal tumor ablation and is traditionally administered with percutaneous or surgical approaches. (Verma \& Dhar, 2008) The feasibility and effectiveness of EUS-guided RFA has been evaluated in animal models and the probe is deployed by a 19 gauge needle inducing coagulative necrosis. (Ramesh \& 
Varadarajulu, 2008) Further application of this technique has been impeded because of the lack of a retractable needle electrode array to ablate large areas. This was overcome by the development of a retractable umbrella-shaped electrode array that has delivered effective coagulation necrosis of large areas in the porcine model. (Varadarajulu et al, 2009)
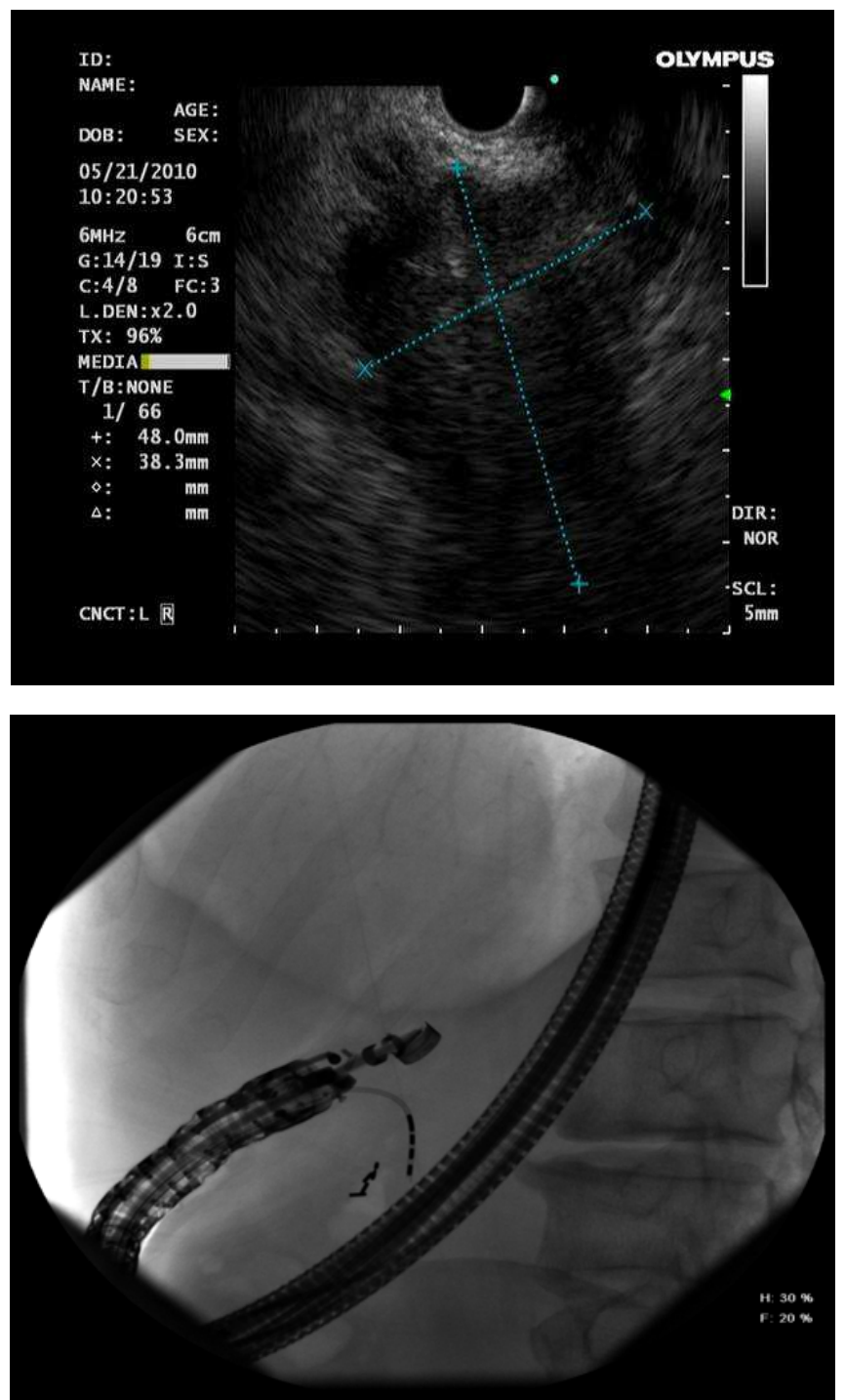

Fig. 7. 66 year-old male with locally advanced, non resectable, pancreatic cancer that underwent EUS-guided of fiducials in the pancreatic head for stereotactic radiotherapy. A $5 \mathrm{~cm}$ pancreatic head mass was identified by EUS (left image), followed by placement of a total of 9 gold fiducials into the inferior and superior aspects of the tumor under fluoroscopy (right image) 
Another experimental technique is photodynamic therapy (PDT), which involves the systemic administration of a photosensitizing agent, followed by placement of lightdiffusing photodynamic fibers into the target malignant tissue. This is usually accomplished percutaneously, but it has recently been placed endoscopically with EUS guidance in the pancreas of porcine models. (Verma \& Dhar, 2008) In animal models, the EUS-guided PDT of pancreas and other organs has proved to be safe and effective. (Chan et al, 2004)

These two EUS-guided ablative techniques, RFA and PDT, have only been performed in animal models and further studies in the safety and efficacy in humans are needed before considering their use in the palliation of advanced pancreatic cancer.

\section{Conclusion}

Endoscopy is a constantly evolving field with a major role in the diagnosis of pancreatic cancer as well as palliation of advanced cases. Pancreatic cancer must be managed with a multidisciplinary approach. EUS is the most frequently used modality for the diagnosis and staging of pancreatic cancer. Treatment with curative intention involves surgery, with the use of adjuvant therapy (chemotherapy and/ or radiation) in some cases. Most cases are diagnosed when curative resection is not possible and different endoscopic approaches can be used in a palliative attempt for symptomatic relieve of pain, jaundice or obstruction.

\section{References}

Agarwal B, Abu-Hamda E, Molke KL, Correa AM, Ho L. Endoscopic ultrasound-guided fine needle aspiration and multidetector spiral $\mathrm{CT}$ in the diagnosis of pancreatic cancer. Am J Gastroenterol 2004;99:844-50.

Al-Haddad M, Eloubeidi MA. Interventional EUS for the diagnosis and treatment of locally advanced pancreatic cancer. JOP 2010;11:1-7.

Ammar T, Cote GA, Creach KM, Kohlmeier C, Parikh PJ, Azar RR. Fiducial placement for stereotactic radiation by using EUS: feasibility when using a marker compatible with a standard 22-gauge needle. Gastrointest Endosc 2010;71:630-3.

Arguedas MR, Heudebert GH, Stinnett AA, Wilcox CM. Biliary stents in malignant obstructive jaundice due to pancreatic carcinoma: a cost-effectiveness analysis. Am J Gastroenterol 2002;97:898-904.

Artifon EL, Takada J, Okawa L, Moura EG, Sakai P. EUS-guided choledochoduodenostomy for biliary drainage in unresectable pancreatic cancer: a case series. JOP 2010;11:597-600.

Ascunce G, Ribeiro A, Reis I, Rocha-Lima C, Sleeman D, Merchan J, Levi J. EUS visualization and direct celiac ganglia neurolysis predicts better pain relief in patients with pancreatic malignancy (with video). Gastrointest Endosc 2011;73:26774.

Aslanian H, Salem RR, Marginean C, Robert M, Lee JH, Topazian M. EUS-guided ethanol injection of normal porcine pancreas: a pilot study. Gastrointest Endosc 2005;62:723-7.

Becker V, Wallace MB, Fockens P, von Delius S, Woodward TA, Raimondo M, Voermans RP, Meining A. Needle-based confocal endomicroscopy for in vivo histology of 
intra-abdominal organs: first results in a porcine model (with videos). Gastrointest Endosc 2010;71:1260-6.

Boulay BR, Gardner TB, Gordon SR. Occlusion rate and complications of plastic biliary stent placement in patients undergoing neoadjuvant chemoradiotherapy for pancreatic cancer with malignant biliary obstruction. J Clin Gastroenterol 2010;44:452-5.

Bret PM, Nicolet V, Labadie M. Percutaneous fine-needle aspiration biopsy of the pancreas. Diagn Cytopathol 1986;2:221-7.

Brugge WR, Lauwers GY, Sahani D, Fernandez-del Castillo C, Warshaw AL. Cystic neoplasms of the pancreas. N Engl J Med 2004;351:1218-26.

Brugge WR, Lewandrowski K, Lee-Lewandrowski E, Centeno BA, Szydlo T, Regan S, del Castillo CF, Warshaw AL. Diagnosis of pancreatic cystic neoplasms: a report of the cooperative pancreatic cyst study. Gastroenterology 2004;126:1330-6.

Caturelli E, Rapaccini GL, Anti M, Fabiano A, Fedeli G. Malignant seeding after fine-needle aspiration biopsy of the pancreas. Diagn Imaging Clin Med 1985;54:88-91.

Chan HH, Nishioka NS, Mino M, Lauwers GY, Puricelli WP, Collier KN, Brugge WR. EUSguided photodynamic therapy of the pancreas: a pilot study. Gastrointest Endosc 2004;59:95-9.

Chang KJ. EUS-guided fine needle injection (FNI) and anti-tumor therapy. Endoscopy 2006;38 Suppl 1:S88-93.

Chen VK, Arguedas MR, Baron TH. Expandable metal biliary stents before pancreaticoduodenectomy for pancreatic cancer: a Monte-Carlo decision analysis. Clin Gastroenterol Hepatol 2005;3:1229-37.

Chen YK. Pancreatoscopy: present and future role. Curr Gastroenterol Rep 2007;9:136-43.

Chhieng DC, Jhala D, Jhala N, Eltoum I, Chen VK, Vickers S, Heslin MJ, Wilcox CM, Eloubeidi MA. Endoscopic ultrasound-guided fine-needle aspiration biopsy: a study of 103 cases. Cancer 2002;96:232-9.

Davids PH, Groen AK, Rauws EA, Tytgat GN, Huibregtse K. Randomised trial of selfexpanding metal stents versus polyethylene stents for distal malignant biliary obstruction. Lancet 1992;340:1488-92.

DeWitt J, Devereaux B, Chriswell M, McGreevy K, Howard T, Imperiale TF, Ciaccia D, Lane KA, Maglinte D, Kopecky K, LeBlanc J, McHenry L, Madura J, Aisen A, Cramer H, Cummings $\mathrm{O}$, Sherman S. Comparison of endoscopic ultrasonography and multidetector computed tomography for detecting and staging pancreatic cancer. Ann Intern Med 2004;141:753-63.

DeWitt J, DiMaio CJ, Brugge WR. Long-term follow-up of pancreatic cysts that resolve radiologically after EUS-guided ethanol ablation. Gastrointest Endosc 2010;72:8626.

Eloubeidi MA, Tamhane A. EUS-guided FNA of solid pancreatic masses: a learning curve with 300 consecutive procedures. Gastrointest Endosc 2005;61:700-8.

Eloubeidi MA, Tamhane A, Varadarajulu S, Wilcox CM. Frequency of major complications after EUS-guided FNA of solid pancreatic masses: a prospective evaluation. Gastrointest Endosc 2006;63:622-9.

Eloubeidi MA, Varadarajulu S, Desai S, Shirley R, Heslin MJ, Mehra M, Arnoletti JP, Eltoum I, Wilcox CM, Vickers SM. A prospective evaluation of an algorithm incorporating routine preoperative endoscopic ultrasound-guided fine needle aspiration in suspected pancreatic cancer. J Gastrointest Surg 2007;11:813-9. 
Erickson RA. EUS-guided FNA. Gastrointest Endosc 2004;60:267-79.

Ferrari Junior AP, Lichtenstein DR, Slivka A, Chang C, Carr-Locke DL. Brush cytology during ERCP for the diagnosis of biliary and pancreatic malignancies. Gastrointest Endosc 1994;40:140-5.

Ferrucci JT, Wittenberg J, Margolies MN, Carey RW. Malignant seeding of the tract after thin-needle aspiration biopsy. Radiology 1979;130:345-6.

Fujita N, Noda Y, Kobayashi G, Kimura K, Ito K. Endoscopic approach to early diagnosis of pancreatic cancer. Pancreas 2004;28:279-81.

Furukawa T, Oohashi K, Yamao K, Naitoh Y, Hirooka Y, Taki T, Itoh A, Hayakawa S, Watanabe $\mathrm{Y}$, Goto H, Hayakawa T. Intraductal ultrasonography of the pancreas: development and clinical potential. Endoscopy 1997;29:561-9.

Gan SI, Thompson CC, Lauwers GY, Bounds BC, Brugge WR. Ethanol lavage of pancreatic cystic lesions: initial pilot study. Gastrointest Endosc 2005;61:746-52.

Giovannini M. Concentration-dependent ablation of pancreatic tissue by EUS-guided ethanol injection. Gastrointest Endosc 2007;65:278-80.

Gress FG, Hawes RH, Savides TJ, Ikenberry SO, Cummings O, Kopecky K, Sherman S, Wiersema M, Lehman GA. Role of EUS in the preoperative staging of pancreatic cancer: a large single-center experience. Gastrointest Endosc 1999;50:786-91.

Gunaratnam NT, Sarma AV, Norton ID, Wiersema MJ. A prospective study of EUS-guided celiac plexus neurolysis for pancreatic cancer pain. Gastrointest Endosc 2001;54:316-24.

Hawes RF, P. Endosonography. Elsevier, 2006.

Hawes RH. The evolution of endoscopic ultrasound: improved imaging, higher accuracy for fine needle aspiration and the reality of endoscopic ultrasound-guided interventions. Curr Opin Gastroenterol 2010;26:436-44.

Iglesias-Garcia J, Larino-Noia J, Abdulkader I, Forteza J, Dominguez-Munoz JE. EUS elastography for the characterization of solid pancreatic masses. Gastrointest Endosc 2009;70:1101-8.

Inoue H, Mizuno N, Sawaki A, Takahashi K, Aoki M, Bhatia V, Matuura K, Tabata T, Yamao K. Life-threatening delayed-onset bleeding after endoscopic ultrasound-guided 19gauge Trucut needle biopsy of a gastric stromal tumor. Endoscopy 2006;38 Suppl 2:E38.

Institute NC. Surveillance Epidemiology and End Results. http:/ / seer.cancer.gov/statfacts/ html/pancreas.html, 2011.

Iqbal S, Stevens PD. Cholangiopancreatoscopy for targeted biopsies of the bile and pancreatic ducts. Gastrointest Endosc Clin N Am 2009;19:567-77.

Irisawa A, Hikichi T, Shibukawa G, Takagi T, Wakatsuki T, Takahashi Y, Imamura H, Sato A, Sato M, Ikeda T, Suzuki R, Obara K, Ohira H. Pancreatobiliary drainage using the EUS-FNA technique: EUS-BD and EUS-PD. J Hepatobiliary Pancreat Surg 2009;16:598-604.

Ishikawa T, Itoh A, Kawashima H, Ohno E, Matsubara H, Itoh Y, Nakamura Y, Nakamura M, Miyahara R, Hayashi K, Ishigami M, Katano Y, Ohmiya N, Goto H, Hirooka Y. Usefulness of EUS combined with contrast-enhancement in the differential diagnosis of malignant versus benign and preoperative localization of pancreatic endocrine tumors. Gastrointest Endosc 2010;71:951-9. 
Itoi $\mathrm{T}$, Neuhaus $\mathrm{H}$, Chen YK. Diagnostic value of image-enhanced video cholangiopancreatoscopy. Gastrointest Endosc Clin N Am 2009;19:557-66.

Jing X, Wamsteker EJ, Li H, Pu RT. Combining fine needle aspiration with brushing cytology has improved yields in diagnosing pancreatic ductal adenocarcinoma. Diagn Cytopathol 2009;37:574-8.

Kaassis M, Boyer J, Dumas R, Ponchon T, Coumaros D, Delcenserie R, Canard JM, Fritsch J, Rey JF, Burtin P. Plastic or metal stents for malignant stricture of the common bile duct? Results of a randomized prospective study. Gastrointest Endosc 2003;57:17882.

Kameya S, Kuno N, Kasugai T. The diagnosis of pancreatic cancer by pancreatic juice cytology. Acta Cytol 1981;25:354-60.

Kaufman M, Singh G, Das S, Concha-Parra R, Erber J, Micames C, Gress F. Efficacy of endoscopic ultrasound-guided celiac plexus block and celiac plexus neurolysis for managing abdominal pain associated with chronic pancreatitis and pancreatic cancer. J Clin Gastroenterol 2010;44:127-34.

Kipp BR, Fritcher EG, Clayton AC, Gores GJ, Roberts LR, Zhang J, Levy MJ, Halling KC. Comparison of KRAS mutation analysis and FISH for detecting pancreatobiliary tract cancer in cytology specimens collected during endoscopic retrograde cholangiopancreatography. J Mol Diagn 2010;12:780-6.

Klapman JB, Chang KJ. Endoscopic ultrasound-guided fine-needle injection. Gastrointest Endosc Clin N Am 2005;15:169-77, x.

Larghi A, Verna EC, Stavropoulos SN, Rotterdam H, Lightdale CJ, Stevens PD. EUS-guided trucut needle biopsies in patients with solid pancreatic masses: a prospective study. Gastrointest Endosc 2004;59:185-90.

Levy MJ. Endoscopic ultrasound-guided trucut biopsy of the pancreas: prospects and problems. Pancreatology 2007;7:163-6.

Matsumoto K, Yamao K, Ohashi K, Watanabe Y, Sawaki A, Nakamura T, Matsuura A, Suzuki T, Fukutomi A, Baba T, Okubo K, Tanaka K, Moriyama I, Shimizu Y. Acute portal vein thrombosis after EUS-guided FNA of pancreatic cancer: case report. Gastrointest Endosc 2003;57:269-71.

Matthes K, Mino-Kenudson M, Sahani DV, Holalkere N, Brugge WR. Concentrationdependent ablation of pancreatic tissue by EUS-guided ethanol injection. Gastrointest Endosc 2007;65:272-7.

McGuire DE, Venu RP, Brown RD, Etzkorn KP, Glaws WR, Abu-Hammour A. Brush cytology for pancreatic carcinoma: an analysis of factors influencing results. Gastrointest Endosc 1996;44:300-4.

Meining A. Confocal endomicroscopy. Gastrointest Endosc Clin N Am 2009;19:629-35.

Meining A, Phillip V, Gaa J, Prinz C, Schmid RM. Pancreaticoscopy with miniprobe-based confocal laser-scanning microscopy of an intraductal papillary mucinous neoplasm (with video). Gastrointest Endosc 2009;69:1178-80.

Mennone A, Nathanson MH. Needle-based confocal laser endomicroscopy to assess liver histology in vivo. Gastrointest Endosc 2011;73:338-44.

Moss AC, Morris E, Mac Mathuna P. Palliative biliary stents for obstructing pancreatic carcinoma. Cochrane Database Syst Rev 2006:CD004200.

Nguyen NQ, Binmoeller KF, Shah JN. Cholangioscopy and pancreatoscopy (with videos). Gastrointest Endosc 2009;70:1200-10. 
Nguyen-Tang T, Binmoeller KF, Sanchez-Yague A, Shah JN. Endoscopic ultrasound (EUS)guided transhepatic anterograde self-expandable metal stent (SEMS) placement across malignant biliary obstruction. Endoscopy 2010;42:232-6.

Nishino T, Oyama H, Toki F, Shiratori K. Differentiation between autoimmune pancreatitis and pancreatic carcinoma based on endoscopic retrograde cholangiopancreatography findings. J Gastroenterol 2010;45:988-96.

O'Toole D, Palazzo L, Arotcarena R, Dancour A, Aubert A, Hammel P, Amaris J, Ruszniewski P. Assessment of complications of EUS-guided fine-needle aspiration. Gastrointest Endosc 2001;53:470-4.

Palazzo L, Roseau G, Gayet B, Vilgrain V, Belghiti J, Fekete F, Paolaggi JA. Endoscopic ultrasonography in the diagnosis and staging of pancreatic adenocarcinoma. Results of a prospective study with comparison to ultrasonography and CT scan. Endoscopy 1993;25:143-50.

Park WG, Yan BM, Schellenberg D, Kim J, Chang DT, Koong A, Patalano C, Van Dam J. EUS-guided gold fiducial insertion for image-guided radiation therapy of pancreatic cancer: 50 successful cases without fluoroscopy. Gastrointest Endosc 2010;71:513-8.

Puli SR, Reddy JB, Bechtold ML, Antillon MR, Brugge WR. EUS-guided celiac plexus neurolysis for pain due to chronic pancreatitis or pancreatic cancer pain: a metaanalysis and systematic review. Dig Dis Sci 2009;54:2330-7.

Ramesh J, Varadarajulu S. Interventional endoscopic ultrasound. Dig Dis 2008;26:347-55.

Rivadeneira DE, Pochapin M, Grobmyer SR, Lieberman MD, Christos PJ, Jacobson I, Daly JM. Comparison of linear array endoscopic ultrasound and helical computed tomography for the staging of periampullary malignancies. Ann Surg Oncol 2003;10:890-7.

Rogart JN. The plastic biliary stent: an obsolete device for managing pancreatic cancer? J Clin Gastroenterol 2010;44:389-90.

Rogart JN, Boghos A, Rossi F, Al-Hashem H, Siddiqui UD, Jamidar P, Aslanian H. Analysis of endoscopic management of occluded metal biliary stents at a single tertiary care center. Gastrointest Endosc 2008;68:676-82.

Sakamoto H, Kitano M, Komaki T, Noda K, Chikugo T, Dote K, Takeyama Y, Das K, Yamao K, Kudo M. Prospective comparative study of the EUS guided 25-gauge FNA needle with the 19-gauge Trucut needle and 22-gauge FNA needle in patients with solid pancreatic masses. J Gastroenterol Hepatol 2009;24:384-90.

Sanders MK, Moser AJ, Khalid A, Fasanella KE, Zeh HJ, Burton S, McGrath K. EUS-guided fiducial placement for stereotactic body radiotherapy in locally advanced and recurrent pancreatic cancer. Gastrointest Endosc 2010;71:1178-84.

Sendino O, Fernandez-Esparrach G, Sole M, Colomo L, Pellise M, Llach J, Navarro S, Bordas JM, Gines A. Endoscopic ultrasonography-guided brushing increases cellular diagnosis of pancreatic cysts: A prospective study. Dig Liver Dis 2010;42:877-81.

Siddiqui AA, Sreenarasimhaiah J, Lara LF, Harford W, Lee C, Eloubeidi MA. Endoscopic ultrasound-guided transduodenal placement of a fully covered metal stent for palliative biliary drainage in patients with malignant biliary obstruction. Surg Endosc 2011;25:549-55. 
Siddiqui UD, Rossi F, Rosenthal LS, Padda MS, Murali-Dharan V, Aslanian HR. EUS-guided FNA of solid pancreatic masses: a prospective, randomized trial comparing 22gauge and 25-gauge needles. Gastrointest Endosc 2009;70:1093-7.

Smith FP, Macdonald JS, Schein PS, Ornitz RD. Cutaneous seeding of pancreatic cancer by skinny-needle aspiration biopsy. Arch Intern Med 1980;140:855.

Society AC. Learn About Cancer. Pancreatic Cancer. http://www.cancer.org/Cancer/ PancreaticCancer/DetailedGuide/pancreatic-cancer-what-is-pancreatic-cancer, 2011.

Sun S, Xu H, Xin J, Liu J, Guo Q, Li S. Endoscopic ultrasound-guided interstitial brachytherapy of unresectable pancreatic cancer: results of a pilot trial. Endoscopy 2006;38:399-403.

Telford JJ, Carr-Locke DL. The role of ERCP and pancreatoscopy in cystic and intraductal tumors. Gastrointest Endosc Clin N Am 2002;12:747-57.

Thomas T, Bebb J, Mannath J, Ragunath K, Kaye PV, Aithal GP. EUS-guided pancreatic cyst brushing: a comparative study in a tertiary referral centre. JOP 2010;11:163-9.

Thomas T, Kaye PV, Ragunath K, Aithal G. Efficacy, safety, and predictive factors for a positive yield of EUS-guided Trucut biopsy: a large tertiary referral center experience. Am J Gastroenterol 2009;104:584-91.

Trevino JM, Varadarajulu S. Endoscopic ultrasonography-guided ablation therapy. J Hepatobiliary Pancreat Sci 2011;18:304-10.

Uchida N, Kamada H, Tsutsui K, Ono M, Aritomo Y, Masaki T, Kushida Y, Haba R, Nakatsu $\mathrm{T}$, Kuriyama S. Utility of pancreatic duct brushing for diagnosis of pancreatic carcinoma. J Gastroenterol 2007;42:657-62.

Vandervoort J, Soetikno RM, Montes H, Lichtenstein DR, Van Dam J, Ruymann FW, Cibas ES, Carr-Locke DL. Accuracy and complication rate of brush cytology from bile duct versus pancreatic duct. Gastrointest Endosc 1999;49:322-7.

Varadarajulu S, Fraig M, Schmulewitz N, Roberts S, Wildi S, Hawes RH, Hoffman BJ, Wallace MB. Comparison of EUS-guided 19-gauge Trucut needle biopsy with EUSguided fine-needle aspiration. Endoscopy 2004;36:397-401.

Varadarajulu S, Jhala NC, Drelichman ER. EUS-guided radiofrequency ablation with a prototype electrode array system in an animal model (with video). Gastrointest Endosc 2009;70:372-6.

Verna EC, Dhar V. Endoscopic ultrasound-guided fine needle injection for cancer therapy: the evolving role of therapeutic endoscopic ultrasound. Therap Adv Gastroenterol 2008;1:103-9.

Wasan SM, Ross WA, Staerkel GA, Lee JH. Use of expandable metallic biliary stents in resectable pancreatic cancer. Am J Gastroenterol 2005;100:2056-61.

Wiersema MJ, Vilmann P, Giovannini M, Chang KJ, Wiersema LM. Endosonographyguided fine-needle aspiration biopsy: diagnostic accuracy and complication assessment. Gastroenterology 1997;112:1087-95.

Wiersema MJ, Wiersema LM. Endosonography-guided celiac plexus neurolysis. Gastrointest Endosc 1996;44:656-62.

Wittmann J, Kocjan G, Sgouros SN, Deheragoda M, Pereira SP. Endoscopic ultrasoundguided tissue sampling by combined fine needle aspiration and trucut needle biopsy: a prospective study. Cytopathology 2006;17:27-33. 
Yamaguchi T, Shirai Y, Ishihara T, Sudo K, Nakagawa A, Ito H, Miyazaki M, Nomura F, Saisho H. Pancreatic juice cytology in the diagnosis of intraductal papillary mucinous neoplasm of the pancreas: significance of sampling by peroral pancreatoscopy. Cancer 2005;104:2830-6.

Yamao K, Bhatia V, Mizuno N, Sawaki A, Shimizu Y, Irisawa A. Interventional endoscopic ultrasonography. J Gastroenterol Hepatol 2009;24:509-19.

Yasuda K, Mukai H, Fujimoto S, Nakajima M, Kawai K. The diagnosis of pancreatic cancer by endoscopic ultrasonography. Gastrointest Endosc 1988;34:1-8. 


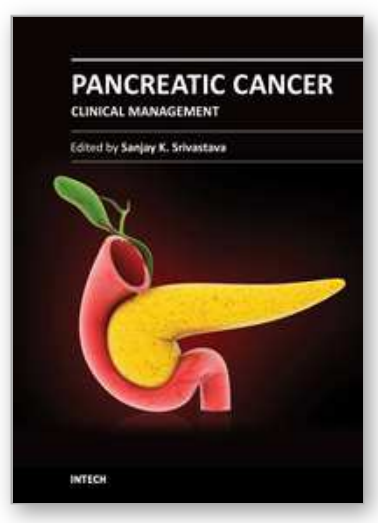

\author{
Pancreatic Cancer - Clinical Management \\ Edited by Prof. Sanjay Srivastava
}

ISBN 978-953-51-0394-3

Hard cover, 312 pages

Publisher InTech

Published online 28, March, 2012

Published in print edition March, 2012

This book covers pancreatic cancer risk factors, treatment and clinical procedures. It provides an outline of pancreatic cancer genetic risk factors, biomarkers and systems biology for the better understanding of disease. As pancreatic cancer suffers from lack of early diagnosis or prognosis markers, this book encompasses stem cell and genetic makers to identify the disease in early stages. The book uncovers the rationale and effectiveness of monotherapy and combination therapy in combating the devastating disease. As immunotherapy is emerging as an attractive approach to cease pancreatic cancer progression, the present book covers various aspects of immunotherapy including innate, adaptive, active, passive and bacterial approaches. Management of anesthesia during surgery and pain after surgery has been discussed. Book also takes the reader through the role of endoscopy and fine needle guided biopsies in diagnosing and observing the disease progression.

\title{
How to reference
}

In order to correctly reference this scholarly work, feel free to copy and paste the following:

Erika Madrigal and Jennifer Chennat (2012). Endoscopic Management of Pancreatic Cancer: From Diagnosis to Palliative Therapy, Pancreatic Cancer - Clinical Management, Prof. Sanjay Srivastava (Ed.), ISBN: 978-95351-0394-3, InTech, Available from: http://www.intechopen.com/books/pancreatic-cancer-clinicalmanagement/endoscopic-management-of-pancreatic-cancer-

\section{INTECH}

open science | open minds

\section{InTech Europe}

University Campus STeP Ri

Slavka Krautzeka 83/A

51000 Rijeka, Croatia

Phone: +385 (51) 770447

Fax: +385 (51) 686166

www.intechopen.com

\section{InTech China}

Unit 405, Office Block, Hotel Equatorial Shanghai

No.65, Yan An Road (West), Shanghai, 200040, China

中国上海市延安西路65号上海国际贵都大饭店办公楼 405 单元

Phone: +86-21-62489820

Fax: $+86-21-62489821$ 
(C) 2012 The Author(s). Licensee IntechOpen. This is an open access article distributed under the terms of the Creative Commons Attribution 3.0 License, which permits unrestricted use, distribution, and reproduction in any medium, provided the original work is properly cited. 